\title{
Electrospun highly corrosion-resistant polystyrene-nickel oxide superhydrophobic nanocomposite coating
}

\author{
A. Bahgat Radwan ${ }^{1}$. Cheirva A. Mannah ${ }^{1}$ - Mostafa H. Sliem ${ }^{1} \cdot$ Noora Hamad S. Al-Qahtani $^{1}$. Paul C. Okonkwo ${ }^{2}$. \\ Elyor Berdimurodov ${ }^{3} \cdot$ Adel M. Mohamed $^{4} \cdot$ Aboubakr M. Abdullah $^{1}$ (i)
}

Received: 10 April 2021 / Accepted: 18 July 2021 / Published online: 6 August 2021

(c) The Author(s) 2021

\begin{abstract}
A key challenge in producing superhydrophobic coatings (SHC) is to tailor the surface morphology on the micro-nanometer scale. In this work, a feasible and straightforward route was employed to manufacture polystyrene/nickel oxide (PSN) nanocomposite superhydrophobic coatings on aluminum alloys to mitigate their corrosion in a saline environment. Different techniques were employed to explore the influence of the addition of NiO nanoparticles to the as-prepared coatings. PSN-2 composite with $\sim 4.3 \mathrm{wt} \%$ of $\mathrm{NiO}$ exhibited the highest water contact angle (WCA) of $155^{\circ} \pm 2$ and contact angle hysteresis $(\mathrm{CAH})$ of $5^{\circ}$.
\end{abstract}

Aboubakr M. Abdullah

bakr@qu.edu.qa

1 Center for Advanced Materials, Qatar University, P.O. Box 2713, Doha, Qatar

2 Mechanical and Mechatronics Engineering Department, College of Engineering, Dhofar University, 211 Salalah, Oman

3 Faculty of Natural Sciences, Karshi State University, Karshi, Uzbekistan 180100

4 Department of Metallurgical and Materials Engineering,

Faculty of Petroleum and Mining Engineering, Suez

University, Suez 43721, Egypt 


\section{Graphic abstract}

EIS Nyquist plots of $3 \mathrm{~g}$ of electrospun polystyrene coatings (a) without and with (b) 0.1 , (c) 0.15 , and (d) $0.2 \mathrm{~g}$ of NiO.
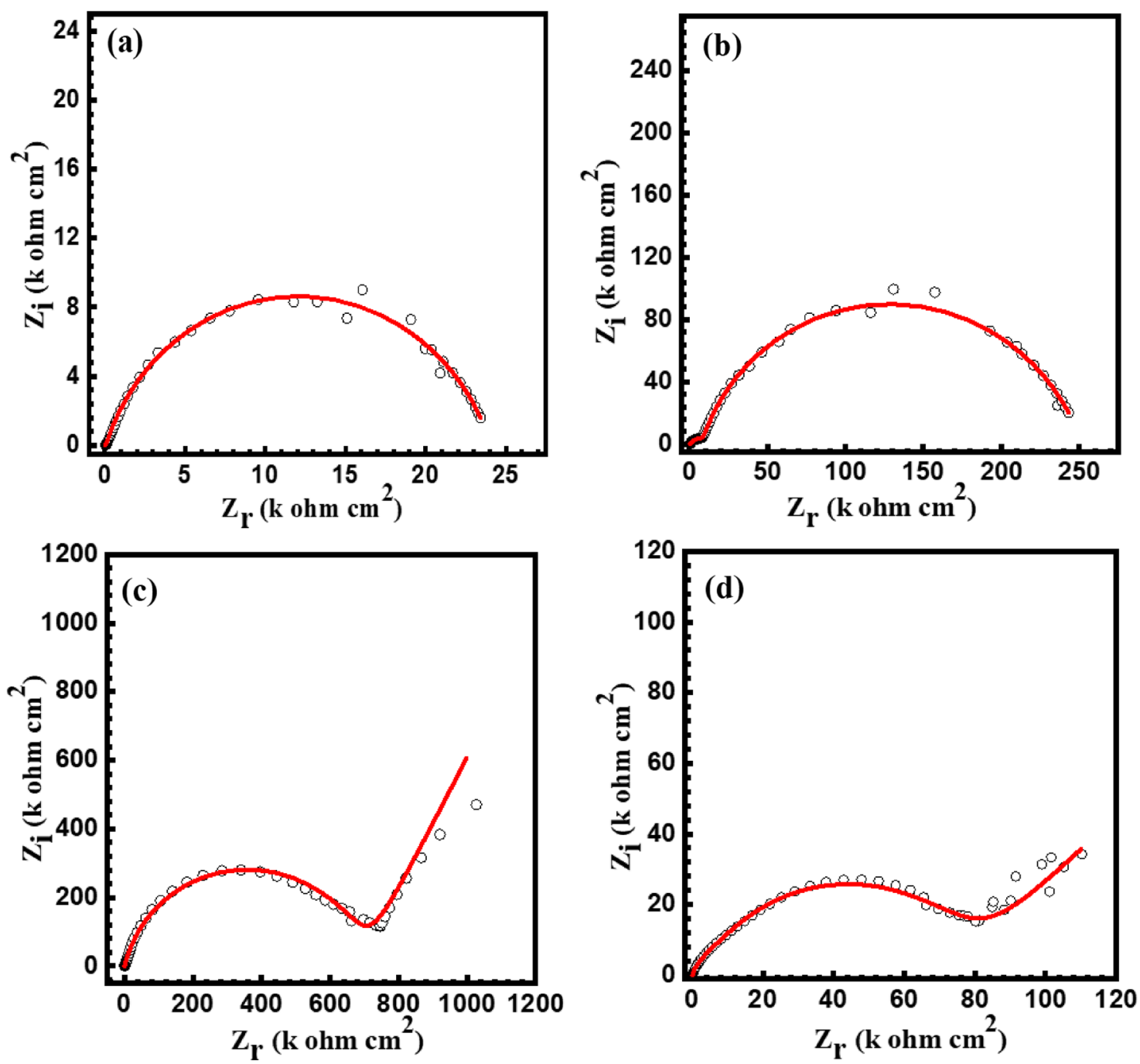

Keywords Wettability $\cdot$ Superhydrophobic $\cdot$ Polystyrene $\cdot$ Nickel oxide $\cdot$ Nanocomposite $\cdot$ Corrosion

\section{Introduction}

Some creatures possess the ability to construct morphologies that can be manipulated to resolve many challenging industrial problems. For example, the lotus leaf's hierarchical roughness and surface chemistry create water-repellency properties with a water contact angle (WCA) higher than $150^{\circ}$ and sliding like beads under the mildest forces [1]. Inspired by nature, scientists apply superhydrophobic coatings on metals and alloys to protect them against corrosive environments. Many industries suffer from corrosion problems resulting in higher maintenance costs, lower efficiencies, and high-risk issues [2]. Aluminum
(Al) and its alloys (AAs) are widespread and have substantial usage in many areas, e.g., packaging, electronics, construction, aviation, and automotive industries [3]. The diversity of aluminum alloy applications arises from the different alloying elements added to pure aluminum, such as copper, silicon, magnesium, manganese, nickel, and zinc. This alloying process results in unique characteristics such as high mechanical strength, excellent thermal and electrical conductors, and corrosion resistance under ambient conditions [4, 5]. However, aluminum alloys are significantly corroded when exposed to corrosive environments. Consequently, variable strategies have been applied to mitigate Al alloys' degradation, such as using corrosion inhibitors, which are chemically or physically 
adsorbed to the metal surface, leading to a reduction in the adsorbition/ingress of the hydrated chloride species [6]. Nevertheless, inhibitors lose their efficiency with time; so, several protective coatings are explored to enhance the inhibitors' efficiencies and prevent corrosion of metallic components [7]. Among these are organic coatings, which display efficient protection against corrosion when metal is placed in a corrosive environment [8]. However, the permeation of aggressive electrolytes through the coatings to the metal/coating interface will dramatically increase the corrosion rate. Consequently, increasing the coating's water-repellency, i.e., using superhydrophobic coatings (SHCs), can be an effective technique to enhance its protection efficiency. It is worth mentioning that two main surface properties control the superhydrophobicity of a coating: (i) minimizing the surface energy and (ii) increasing the surface roughness [9].

The electrospinning technique is commonly used to produce superhydrophobic coatings due to its simplicity, high efficiency, template synthesis, self-assembly, inexpensive, and applicability for plenty of polymers to generate nanofibers $[1,10]$. Many parameters affect the production of electrospun SHC coatings, such as solution properties (viscosity, surface tension, and average molecular weight of the used polymer) and electrospinning process properties, e.g., flow rate, applied voltage, the distance between a needle and substrates, and time [11-14].

Polystyrene (PS) and poly-functionalized polystyrene are widely used in different applications [15]. PS is relatively inexpensive and has a low melting point, which results in the wide usage of PS [16]. Compositing polystyrene with nanoparticles can significantly enhance the surface roughness and, therefore, increase the air trapped in the coating disparities, resulting in a high water contact angle (WCA) $[1,15]$. Different inorganic nanoparticles were exploited with polystyrene to manufacture superhydrophobic coatings, including $\mathrm{SiO}_{2}, \mathrm{TiO}_{2}, \mathrm{MnO}_{2}$, and $\mathrm{Al}_{2} \mathrm{O}_{3}$, leading to hierarchical morphologies [15, 17-19]. Zhao et al. [20] synthesized SHC polyaniline (PANI)/polystyrene (PS) micro/ nanostructure $\left(\mathrm{WCA}=153^{\circ}\right.$ ) on carbon steel using electrospinning, showing a protection efficiency of $99.48 \%$ in $0.1 \mathrm{M} \mathrm{H}_{2} \mathrm{SO}_{4}$. Pawar et al. [21] prepared an SHC using the spin deposition technique on mild steel from a mixture of hydrophobically modified silica particles and polystyrene. The as-prepared coating exhibited WCA and WCAH of $158^{\circ}$ and $9^{\circ}$, respectively, and corrosion resistance of $2 \times 10^{6} \Omega$ $\mathrm{cm}^{2}$ in saline water. Feng et al. [22] successfully grafted polystyrene on $\mathrm{Al}$ alloy displaying a WCA and sliding angle of $153.6^{\circ}$ and $3^{\circ}$, respectively, which results in reducing the $i_{\text {corr }}$, from $1.74 \times 10^{-4} \mathrm{~A} \mathrm{~cm}^{2}$ for the uncoated substrate to $1.16 \times 10^{-5} \mathrm{~A} \mathrm{~cm}^{2}$

We have recently shown that the difference in corrosion resistance of the SHCs with the same WCA could not be attributed to their superhydrophobic nature but to the lowering in the coating's dielectric constant, which affects the water permeability [23]. The corrosion resistance of the asprepared SHC is attributed to the combined effect of the Cassie-Baxter approach and to the reduction of the dielectric constant $\left(\varepsilon^{\prime}\right)$ and the AC conductivity $\left(\sigma^{\prime}\right)$ after the addition of nano-species. Thus, the electrospun nanocomposite coating's electrical dipoles became less dielectrically active and lessened the corrosive electrolyte diffusion.

In the present work, the $\mathrm{Al}$ surface was modified using new electrospun PS-NiO nanocomposite SHCs with different NiO-to-PS ratios, which has not been reported earlier in the literature. The new SHCs are characterized using various techniques, including the water contact angle (WCA) and contact angle hysteresis (CAH), Fourier-transform infrared (FTIR), X-ray diffraction (XRD), and scanning electron microscopy (SEM). The surface roughness is measured using atomic force microscopy (AFM). Moreover, the thermal properties of the samples and the corrosion resistance are tested by differential scanning calorimeter (DSC) and thermal gravimetric analysis (TGA), and the electrochemical impedance spectroscopy EIS, respectively.

\section{Experiment}

\subsection{Materials}

Polystyrene (PS) with an average molecular weight (MW) of 250,000 was imported from Sigma-Aldrich with a specific density of $1.05 \mathrm{~g} \mathrm{~cm}^{-3}$. Nickel oxide $(\mathrm{NiO})$ nanopowder with particle size $<50 \mathrm{~nm}$ was also obtained from Sigma-Aldrich. The solvents like $N, N$-Dimethylacitamide (DMAC), and Tetrahydrofuran (THF) were purchased from BDH chemicals.

\subsection{Coating synthesis}

A $3 \mathrm{~g}$ of polystyrene was dissolved in a $50 \mathrm{ml}$ of mixture which consists of $70 \mathrm{wt} \%$ DMAC and $30 \mathrm{wt} \%$ THF and stirred overnight at $30{ }^{\circ} \mathrm{C}$ to get a sufficiently homogenous solution with the required viscosity for electrospinning. Simultaneously, different $\mathrm{NiO}$ nanoparticle powder amounts were dispersed in $25 \mathrm{ml}$ of THF under stirring for $90 \mathrm{~min}$. The NiO nanoparticle/solvent mixture was then gradually added to the PS solution and stirred for $1 \mathrm{~h}$ at $50{ }^{\circ} \mathrm{C}$. Table 1 shows the variation of the $\mathrm{NiO}$ loadings used to synthesize the different nanocomposite PS-NiO SHCs. Aluminum substrates with $3 \times 3 \mathrm{~cm}^{2}$ size and $2 \mathrm{~mm}$ thickness were used as collectors and coated with the PS-NiO SHCs. Before electrospinning the $\mathrm{PS}-\mathrm{NiO}$ mixture, $\mathrm{Al}$ sheets were polished using different emery papers up to 1200 and after that sonicated in acetone to remove any impurities. 
Table 1 Compositions and electrospinning parameters for pure PS and $\mathrm{PS} / \mathrm{NiO}$ nanocomposite coatings

\begin{tabular}{lllll}
\hline Exp. code & PS $(\mathrm{g})$ & $\mathrm{NiO}(\mathrm{g})$ & Potential $(\mathrm{kV})$ & $\begin{array}{l}\text { Flow rate } \\
\left(\mathrm{mL} \mathrm{h}^{-1}\right)\end{array}$ \\
\hline PS & 3 & - & 18 & 1.5 \\
PSN-1 & 3 & 0.1 & 18 & 1.5 \\
PSN-2 & 3 & 0.15 & 18 & 1.5 \\
PSN-3 & 3 & 0.2 & 18 & 1.5 \\
\hline
\end{tabular}

The electrospinning unit consists of a high voltage supply, syringe pump, and a collector. The optimum distance used to manufacture the superhydrophobic coatings was $15 \mathrm{~cm}$ from the needle tip to the substrates with a cross-sectional diameter of $0.7 \mathrm{~mm}$. The electrospinning flow rate was $1.5 \mathrm{~mL} \mathrm{~h}^{-1}$ at an applied voltage of $18 \mathrm{kV}$ and an operating temperature of $40{ }^{\circ} \mathrm{C}$.

\subsection{Characterization}

A high field-emission scanning electron microscope, HFESEM (FEI NOVA NANOSEM 450, Hillsboro, OR, USA), was used to investigate the morphologies of the as-prepared nanocomposite coatings. All SEM samples were coated with a thin layer of gold to avoid charging and increase the conductivity. WCAs were measured using optical contact angle measuring system (OCA 35, Dataphysics Instruments, Filderstadt, Germany). AFM images were captured using (MFP-3D, Asylum Research, Santa Barbara, CA, USA). AFM measurements were carried out using silicon tip, which has a radius of $10 \mathrm{~nm}$ over a resonance frequency of $70 \mathrm{kHz}$ in addition to a spring constant of $2 \mathrm{Nm}^{-1}$ used for non-contact tapping mode in air. Transmittance FTIR was measured using (PerkinElmer Spectrum 400 FTIR, PerkinElmer, Waltham, MA, USA). The XRD analysis was carried out using (Rigaku, Miniflex2 Desktop, Tokyo, Japan) equipped with $\mathrm{Cu} \mathrm{K}_{\alpha}$ radiations. The structural and phase study of as-prepared catalyst at scanning step of $0.02^{\circ}$ in the $2 \theta$ range from $10^{\circ}$ to $90^{\circ}$. The FTIR spectra of the coated samples were recorded in the range of $400-4000 \mathrm{~cm}^{-1}$. TGA measurements were performed using (4000 PerkinElmer Pyris system). DSC analysis was conducted using a differential scanning calorimeter (DSC 8500, PerkinElmer, USA). The DCS test was carried out in Al crucible using $5 \mathrm{mg}$ weight of specimen. Gamry Reference 3000 potentiostat (Warminster, PA, USA) was utilized to measure the electrochemical performance of $\mathrm{PS} / \mathrm{NiO}$ superhydrophobic coating in $3.5 \mathrm{wt} \% \mathrm{NaCl}$. Gamry Reference 3000 consists of three electrodes, $\mathrm{Ag} / \mathrm{AgCl}$ as a reference electrode, the working electrode (the as-prepared coatings), and graphite as a counter electrode. The coated samples with a surface area of $0.785 \mathrm{~cm}^{2}$ were exposed to $3.5 \mathrm{wt} \% \mathrm{NaCl}$ solution.
EIS measurements were carried out at an open circuit with a wave amplitude of $10 \mathrm{mV}$ over a frequency range of $0.01 \mathrm{~Hz}$ to $100 \mathrm{kHz}$ at room temperature. Before conducting EIS measurements, the samples were immersed $30 \mathrm{~min}$ in the electrolyte to reach the steady-state and set the open circuit potential. EIS data were analyzed using Gamry Echem Analyst software (Version 7.06, Gamry, Warminster, PA, USA).

\section{Results and discussion}

\subsection{Scanning electron microscopy (SEM)}

The different morphologies of the electrospun PS and PS-NiO nanocomposite SHCs at different PS-to-NiO ratios are summarized in the SEM micrographs shown in Fig. 1. The formation of a beaded-fiber structure with different diameters can be seen easily. These beads may be obtained owing to low polystyrene concentrations [24]. Actually, under the test conditions, the creation of spindle beaded fibers has two reasons: (i) the low applied voltages of $18 \mathrm{kV}$ during the electrospinning process and the fast stretching through the charged jet [24] and (ii) low polystyrene concentration, which leads to a significant decline in the elasticity that provides the required resistance to overcome the elongation caused by the electrostatic force [25]. In general, there are three forces accountable for the construction of beads consisting of coulombic, viscoelastic, and surface tension forces and the stretching of the charged jet during the electrospun process. It is noteworthy that $\mathrm{NiO}$ nanoparticles' presence has no considerable influence on the surface morphology of the electrospun polystyrene, as displayed in Fig. 1b-d. It can be observed that the variation in the diameter of the constructed beaded fibers is negligible. A beaded-fibers' texture is desirable since its structure contributes to the coating's roughness, leading to increased trapped air volume between the modified surface inequalities [24].

\subsection{Contact angle measurement}

Figure 2 shows the wettability of the electrospun PS and PS-NiO nanocomposite SHCs. The static contact angle of the as-prepared coatings was investigated using the sessile droplet method at room temperature. Table 2 demonstrates the measured water contact angles and sliding angles for $\mathrm{PS}$ and PS-NiO nanocomposite SHCs. The water contact angles were measured for PS with and without $\mathrm{NiO}$ nanoparticles. The measured WCA of pure electrospun PS is $146^{\circ} \pm 2$. On the other hand, $\mathrm{NiO}$ nanoparticles' addition to PS significantly enhanced the wettability of the as-fabricated coatings. The highest WCA of PS-NiO nanocomposite coatings was $155^{\circ} \pm 1$ for PSN-2, and the lowest contact angle was $150^{\circ} \pm 2$ for PSN-3. As a function of 

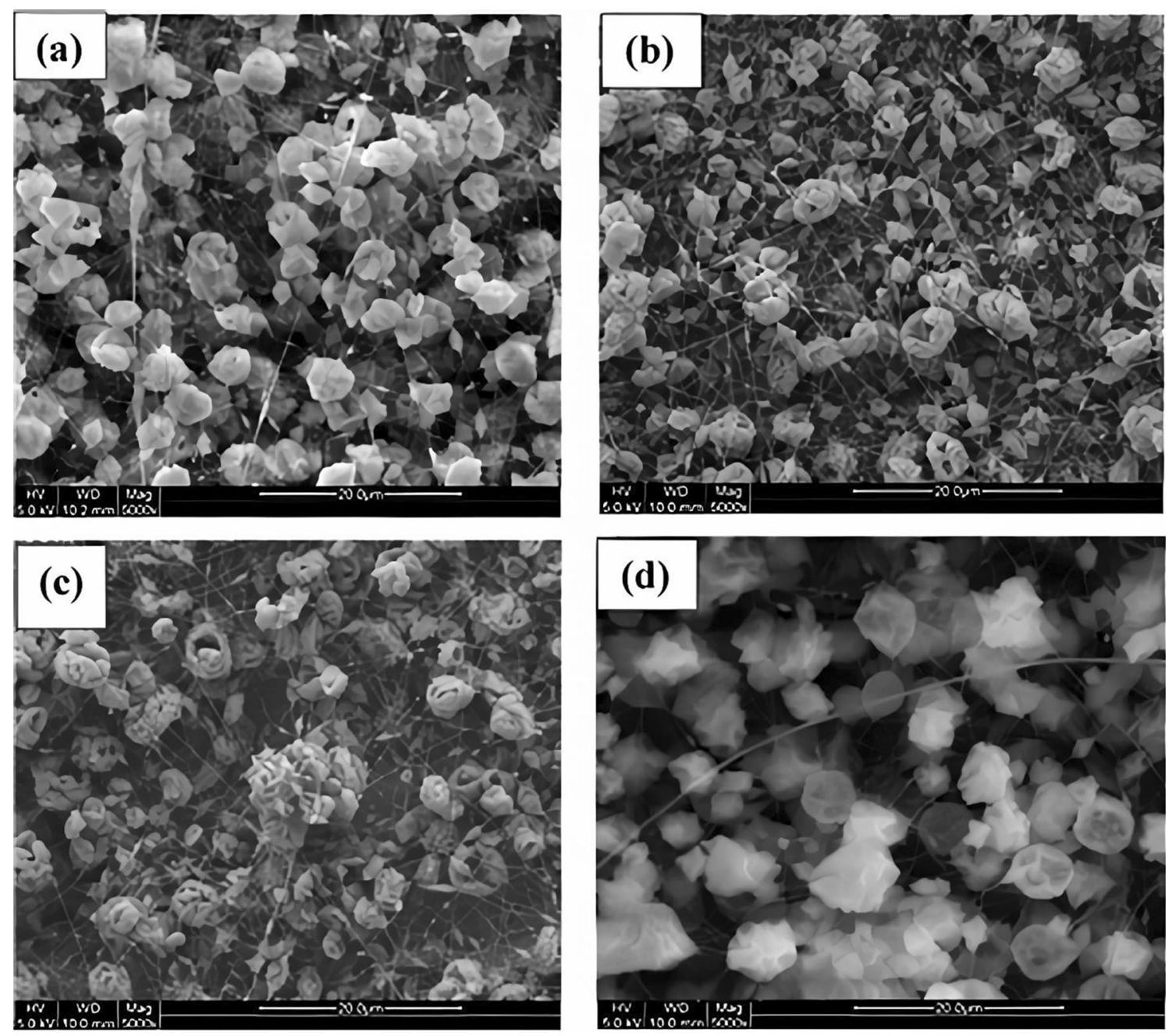

Fig. 1 SEM images of electrospun PS and PS-NiO nanocomposite superhydrophobic coating for a PS, b PSN-1, $\mathbf{c}$ PSN-2, and d PSN-3

$\mathrm{NiO}$ content, the measured WCA had an inflection point due to two opposite effects. At low concentrations of NiO, the increase in the surface roughness due to the addition of the $\mathrm{NiO}$ is the dominant parameter. However, at a higher concentration of $\mathrm{NiO}$, the hydrophilic nature of the $\mathrm{NiO}$ became the dominant factor, which lowered the WCA [20, 26]. The recorded WCA of neat was PS $146^{\circ} \pm 2$; however, the addition of the nanospecies significantly increased the WCA to $153^{\circ}, 155^{\circ} \pm 1$, and $150^{\circ} \pm 2$ for PSN-1, PSN2 , and PSN-3, respectively. The contact angle hysteresis (CAH) for PS and PS-NiO nanocomposite SHCs is displayed in Table 2. The measured CAH of pure PS coating nanoparticles was $25^{\circ} \pm 3$, which markedly reduced after the addition of $\mathrm{NiO}$ nanoparticles to $8^{\circ} \pm 2,5^{\circ} \pm 3$, and $12^{\circ} \pm 2$ for PSN-1, PSN-2, and PSN-3, respectively.

\subsection{Atomic force microscopy (AFM)}

AFM was performed to investigate the surface topography of PS and PS-NiO nanocomposite SHCs, as illustrated in Fig. 3. The pure PS coating showed the lowest value of surface roughness $(114 \mathrm{~nm})$. However, the surface roughness of the $\mathrm{PS}-\mathrm{NiO}$ nanocomposite $\mathrm{SHC}$ increased by the addition of $\mathrm{NiO}$ nanoparticle up to specific content, beyond that limit $R_{a}$ the value was lowered [27]. The $R_{a}$ value of the as-prepared coatings were found to be $131 \pm 5,169 \pm 4$, and $127 \pm 2 \mathrm{~nm}$ for PSN-1, PSN-2, and 
Fig. 2 Snapshots of the measured water contact angle of the pure PS and PS/NiO nanocomposite SHCs

(a)

(b)

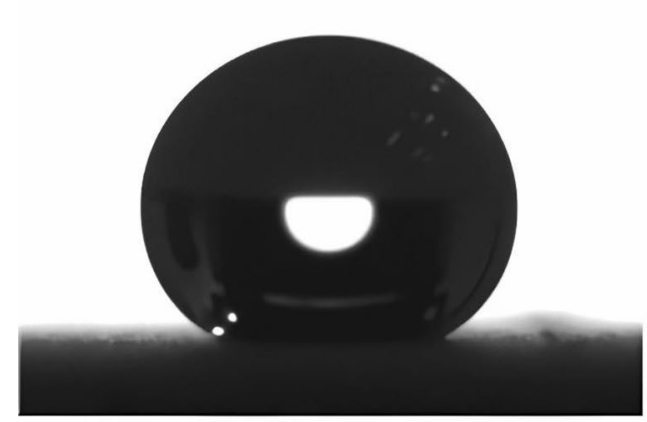

$\mathrm{PS}, \mathrm{WCA}=146^{\circ} \pm 2$

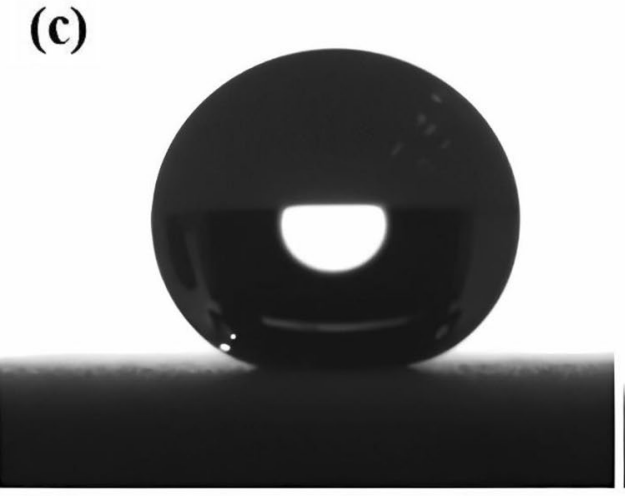

$\mathrm{PSN}-2, \mathrm{WCA}=155^{\circ} \pm 1$

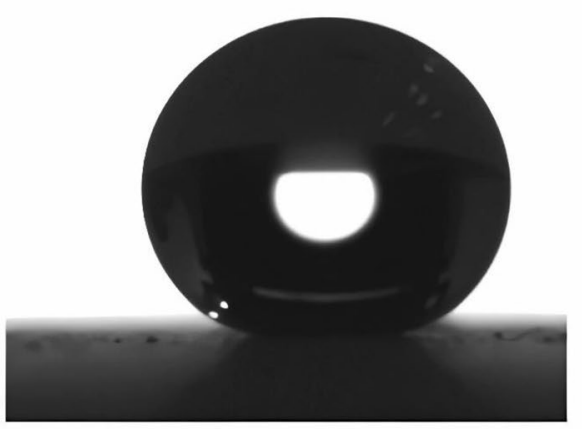

$\mathrm{PSN}-1, \mathrm{WCA}=153^{\circ} \pm 2$

(d)

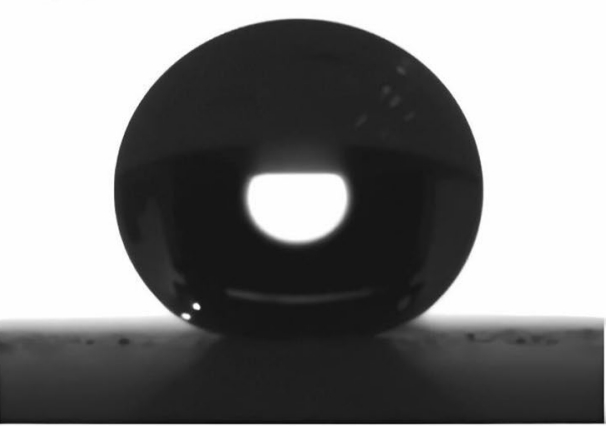

$\mathrm{PSN}-3, \mathrm{WCA}=150^{\circ} \pm 2$
Table 2 WCA and WCAH of the prepared PS and PS/NiO nanocomposite SHCs

\begin{tabular}{lll}
\hline Sample & $\begin{array}{l}\text { Water contact angle } \\
\text { (WCA) }\end{array}$ & $\begin{array}{l}\text { Water contact } \\
\text { angle hyster- } \\
\text { esis } \\
\text { (WCAH) }\end{array}$ \\
\hline PS & $146^{\circ} \pm 2$ & $25^{\circ} \pm 3$ \\
PSN-1 & $153^{\circ} \pm 2$ & $8^{\circ} \pm 2$ \\
PSN-2 & $155^{\circ} \pm 1$ & $5^{\circ} \pm 2$ \\
PSN-3 & $150^{\circ} \pm 2$ & $12^{\circ} \pm 2$ \\
\hline
\end{tabular}

PSN-3, respectively. In general, AFM measurements draw an attention to the impact of the composition ratio of PS to $\mathrm{NiO}$ nanoparticle on the degree of roughness of the prepared coatings. It is worth mentioning that the formed microbeads and nanofiber structures greatly improve the coatings' surface roughness.

\subsection{XRD}

X-ray diffraction patterns of polystyrene and polystyrene/ $\mathrm{NiO}$ nanocomposites are shown in Fig. 4a and b. Characteristic diffraction peaks located at $2 \theta=37.31^{\circ}, 43.4^{\circ}$, $62.9^{\circ}, 75.3^{\circ}$, and $79.4^{\circ}$ are corresponding to (111), (200), (220), (311), and (222) planes of the crystalline $\mathrm{NiO}$ nanoparticles, respectively [28, 29]. The observed broad XRD peak at $2 \theta=19.3^{\circ}$ before and after the addition of $\mathrm{NiO}$ is attributed to the (001) crystal plane, indicating the amorphous halo structure of polystyrene [30]. This peak is linked to the van der Waals space between neighboring chains [31]. The amorphous PS structure could be attributed to the rapid phase change of liquid to solid during the electrospinning process [31]. Two NiO nanoparticles' peaks were identified at $2 \theta=37.2^{\circ}$ and $43.2^{\circ}$ after the addition of polystyrene. It is noteworthy that the addition of $\mathrm{NiO}$ has no significant influence on the amorphous structure of PS. 


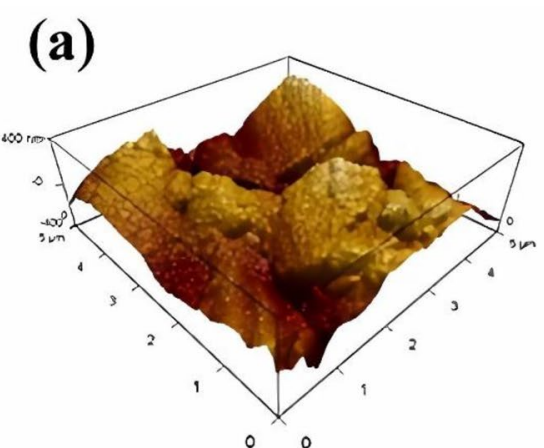

(c)

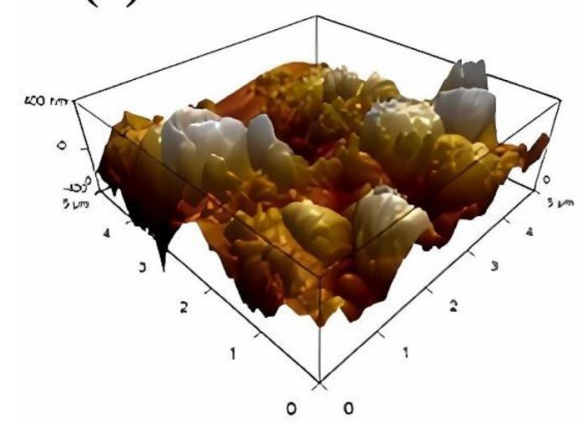

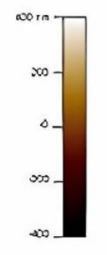

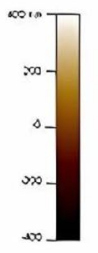

Fig. 3 AFM images of surface of a PS, b PSN-1, c PSN-2, and d PSN-3
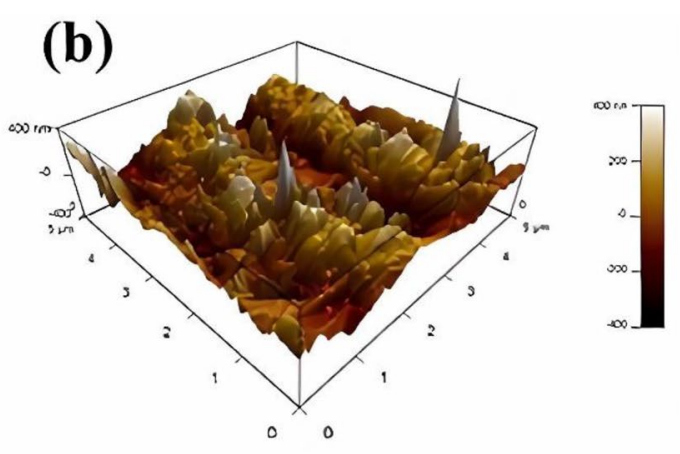

(d)
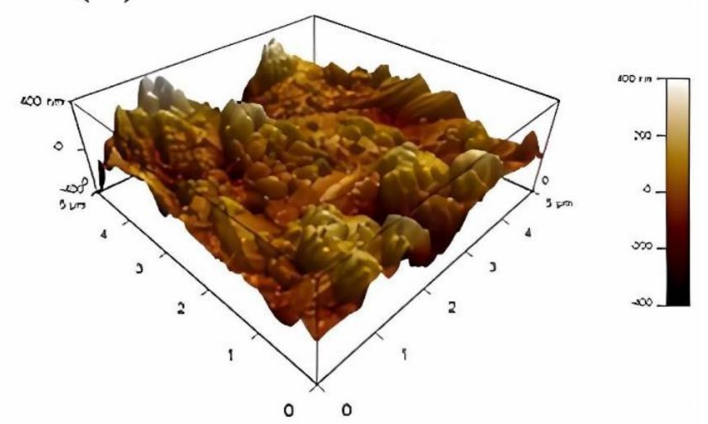
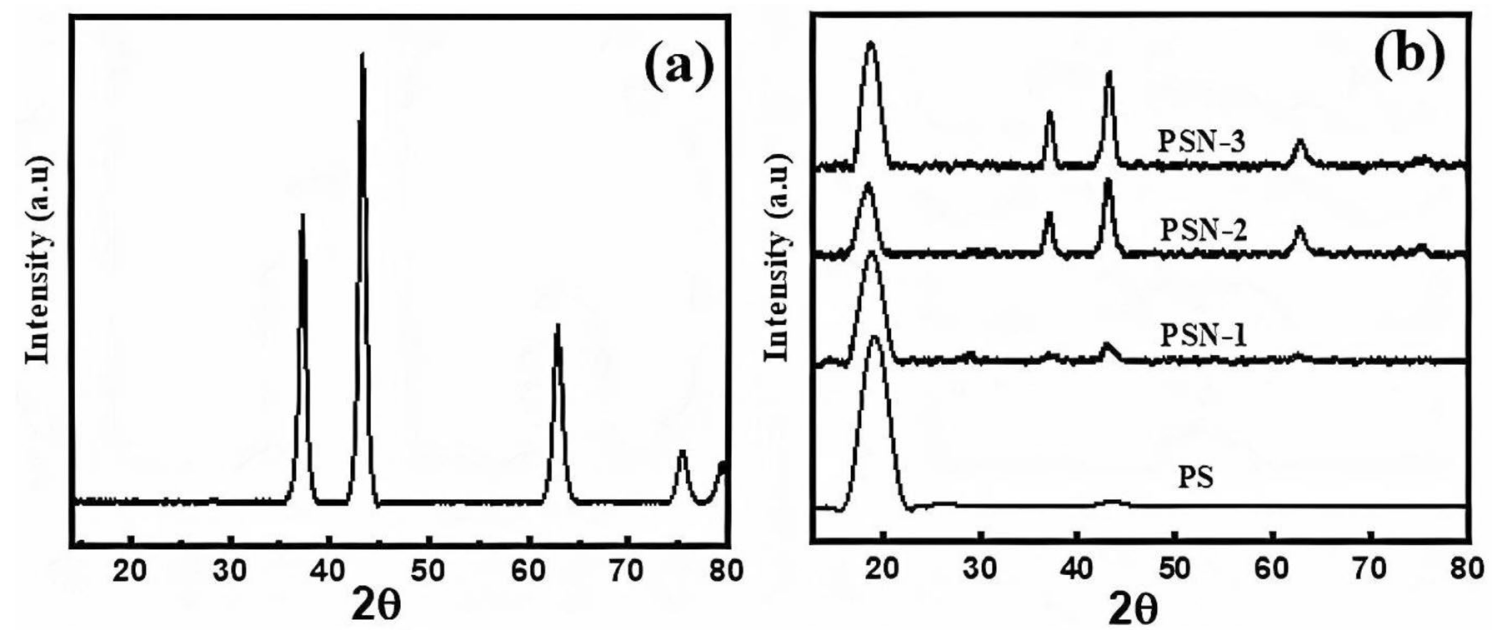

Fig. 4 X-ray diffraction pattern of $\mathbf{a} \mathrm{NiO}$ nanoparticles and $\mathbf{b}$ electrospun polystyrene before and after the addition of NiO nanoparticles

\subsection{FTIR}

FTIR spectra of PS and PS-NiO nanocomposite SHCs are shown in Fig. 5. The spectra of PS coating before and after the addition of $\mathrm{NiO}$ nanoparticles are similar. The strong peaks located at 701 and $763 \mathrm{~cm}^{-1}$ are attributed to $-\mathrm{CH}_{2}$ 


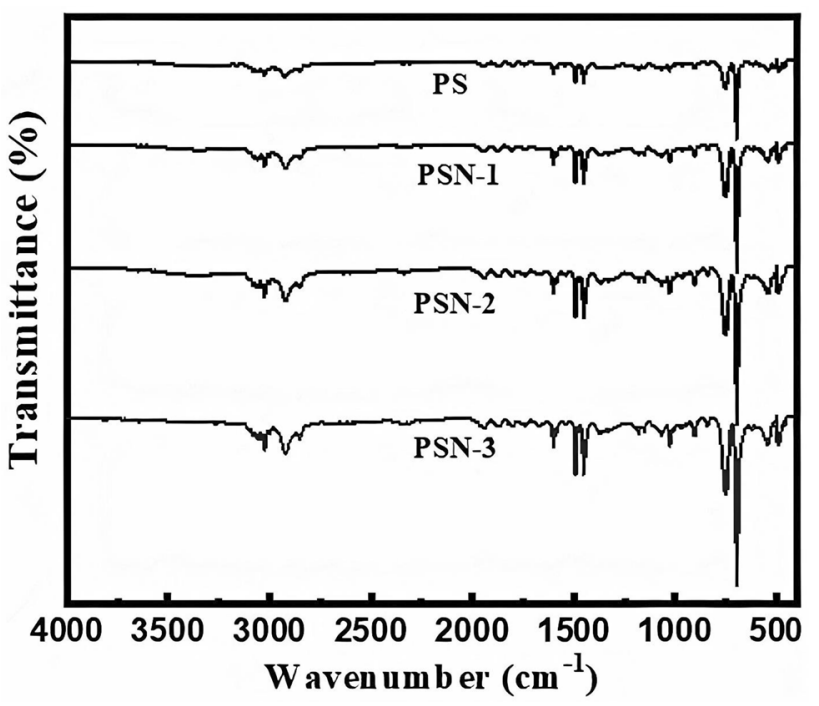

Fig. 5 FTIR spectra for PS and PS-NiO nanocomposite SHCs

rocking mode and $\mathrm{C}-\mathrm{H}$ out-of-plane bend, respectively [32, 33]. The aromatic ring and $\mathrm{C}-\mathrm{C}$ aromatic stretch vibrations are observed at 1096 and $1493 \mathrm{~cm}^{-1}$, respectively $[34,35]$. The observed bands at 2923 and $2855 \mathrm{~cm}^{-1}$ correspond to the $\mathrm{C}-\mathrm{H}$ stretching vibration of the $-\mathrm{CH}_{2}$ and $-\mathrm{CH}$ groups on the main PS chain. However, the peaks located at $3000-3100 \mathrm{~cm}^{-1}$ are accredited to the $\mathrm{C}-\mathrm{H}$ group on the electrospun PS side chain and the aromatic $\mathrm{C}-\mathrm{H}$ stretching vibration [35]. It is worth mentioning that the typical absorption band of $\mathrm{Ni}-\mathrm{O}$ stretching appeared at $430-490 \mathrm{~cm}^{-1}$ in PSN-1, PSN-2, and PSN-3 [36, 37].

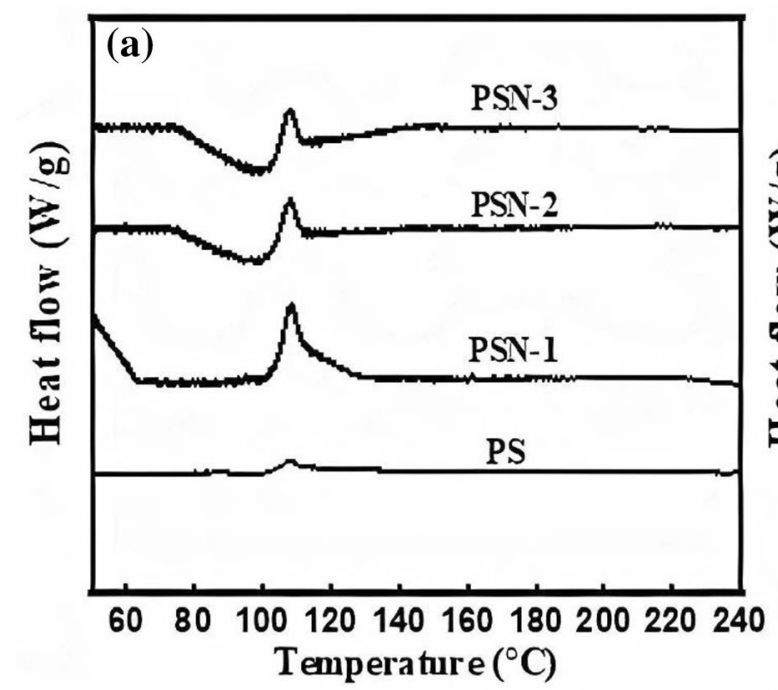

\subsection{Differential scanning calorimetry (DSC)}

Figure 6 displays the melting and crystallization curves of PS and PS-NiO nanocomposite SHCs obtained from the DSC's second heating and first cooling steps. DSC measurements' temperature was raised from -30 to $250{ }^{\circ} \mathrm{C}$ at a scan speed of $10{ }^{\circ} \mathrm{C} \mathrm{min}^{-1}$. The glass transition temperature $\left(T_{\mathrm{g}}\right)$ is observed at $107{ }^{\circ} \mathrm{C}$ for PS and PS-NiO nanocomposite SHCs. The existence of $\mathrm{NiO}$ nanoparticles did not change the $T_{\mathrm{g}}$ of PS. The melting temperature of PS before and after $\mathrm{NiO}$ nanoparticles' addition is almost the same $\left(110^{\circ} \mathrm{C}\right)$, as shown in Fig. 6a. Also, the crystallization behavior of PS and PS-NiO nanocomposite SHCs is identical; no cold crystalline peak is observed, as shown in Fig. 6b. Therefore, PS under these conditions is an amorphous polymer evidenced by the degree of crystallization measured from Eq. (2). The enhancement of the glass transition temperature, melting, and crystallization temperature of polystyrene was very difficult because of phenyl rings' rigidity [38]. The $T_{\mathrm{g}}$ development occurs when polymer components are strongly

Table 3 DSC data for pure PS and PS-NiO nanocomposite SHCs

\begin{tabular}{llll}
\hline Sample & $T_{\mathrm{g}}\left({ }^{\circ} \mathrm{C}\right)$ & $\Delta H_{m}\left(\mathrm{~J} \mathrm{~g}^{-1}\right)$ & $X_{\text {cry }}(\%)$ \\
\hline PS & 107.5 & 2.159 & 4.06 \\
PSN-1 & 107.7 & 1.664 & 3.13 \\
PSN-2 & 108.2 & 1.3 .61 & 2.55 \\
PSN-3 & 107.48 & 1.412 & 2.65 \\
\hline
\end{tabular}

adsorbed onto the surface of the nanospecies leading to reducing the free space to move polymer macromolecules. Consequently, behavioral progress in the $T_{\mathrm{g}}$ proposed a weak

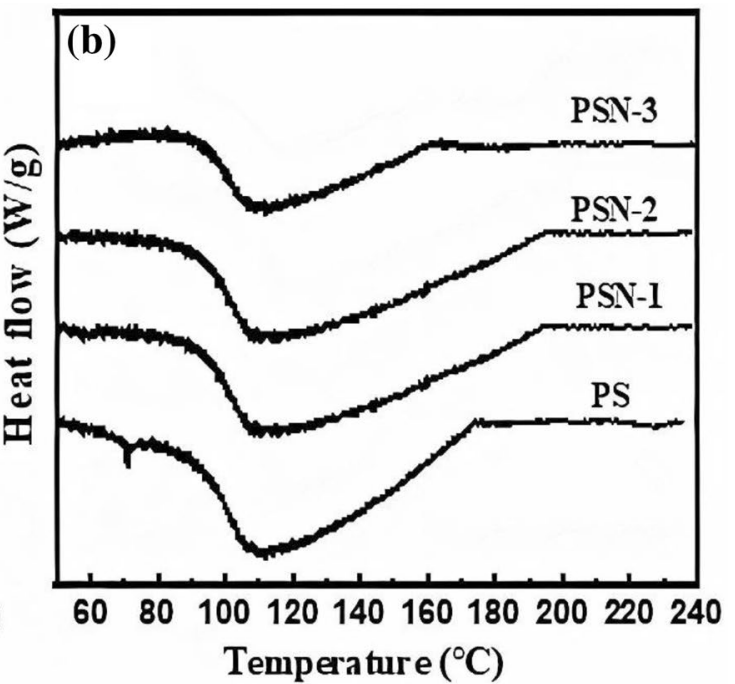

Fig. 6 DSC analysis for PS and PS-NiO nanocomposite SHCs a Heating curves b Cooling curves 
Fig. 7 Thermogravimetric analysis for pure a PS, b PSN-1, c PSN-2, and d PSN-3

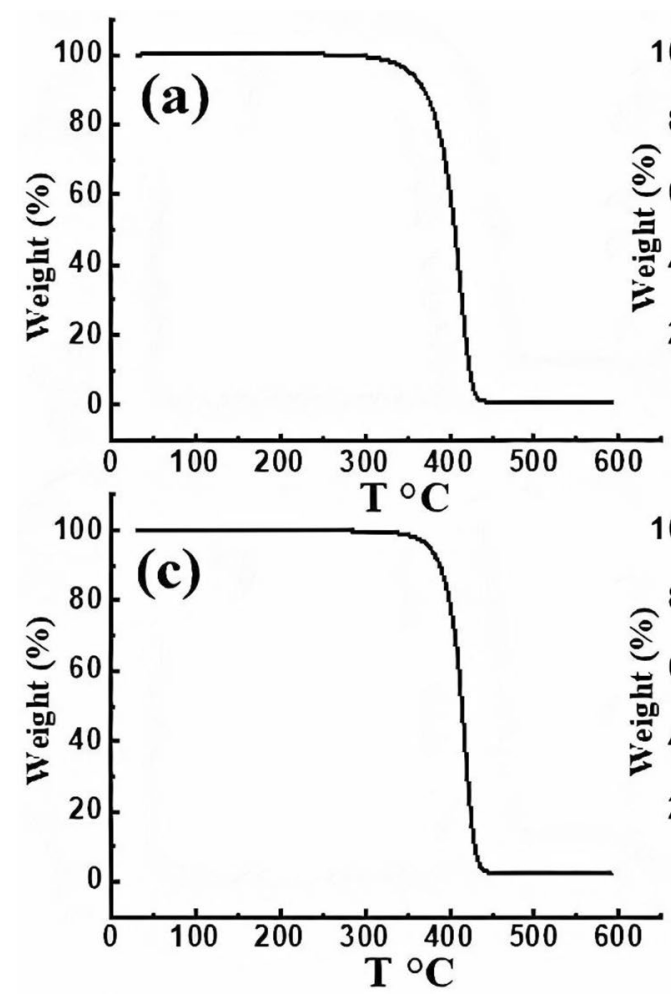

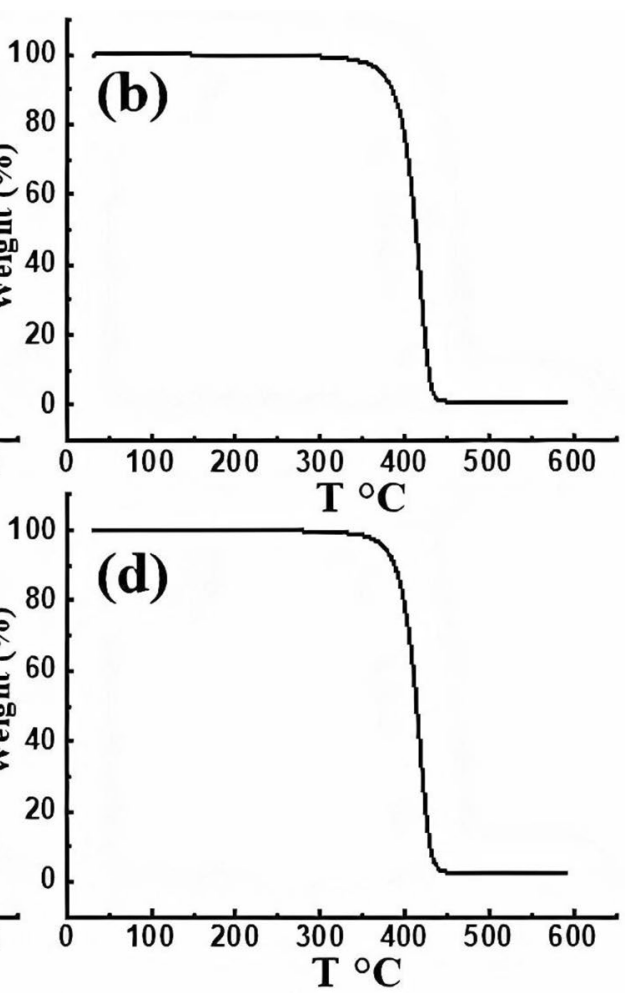

Table 4 TGA data of PS and PS/NiO nanocomposite coatings

\begin{tabular}{llll}
\hline Sample & $T_{\text {onset }}\left({ }^{\circ} \mathrm{C}\right)$ & $T_{50 \%}\left({ }^{\circ} \mathrm{C}\right)$ & $T_{\mathrm{Max}}\left({ }^{\circ} \mathrm{C}\right)$ \\
\hline PS & $354.7 \pm 0.3$ & $405.52 \pm 0.2$ & $440 \pm 0.1$ \\
PSN-1 & $371.0 \pm 0.2$ & $412.63 \pm 0.1$ & $450 \pm 0.2$ \\
PSN-2 & $375.4 \pm 0.1$ & $415.05 \pm 0.4$ & $470 \pm 0.1$ \\
PSN-3 & $375.6 \pm 0.1$ & $417.42 \pm 0.2$ & $470 \pm 0.3$ \\
\hline
\end{tabular}

(a)

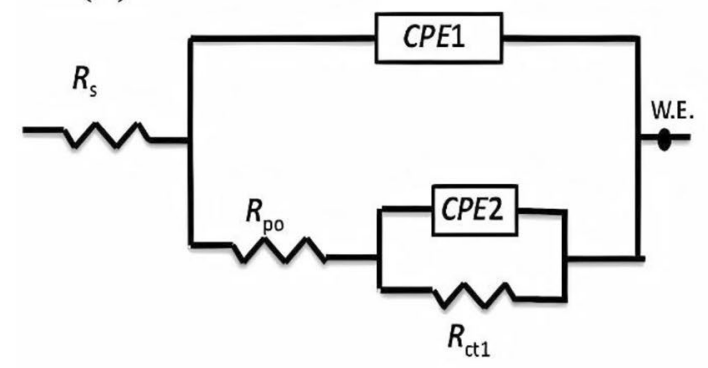

(b)

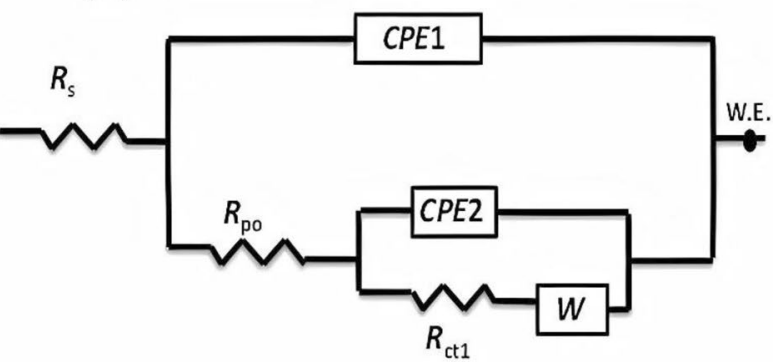

Fig. 8 The equivalent circuit used to fit the EIS data of the as-prepared coatings

interaction between $\mathrm{NiO}$ nanoparticles and PS polymer chains [38]. The degree of crystallinity of the as-fabricated coatings was evaluated before and after the addition of $\mathrm{NiO}$ nanoparticles using the following formula [39, 40]: 
Fig. 9 Nyquist plots of the as-prepared coatings of $\mathbf{a}$ PS, $\mathbf{b}$ PSN-1, c PSN-2, and d PSN-3
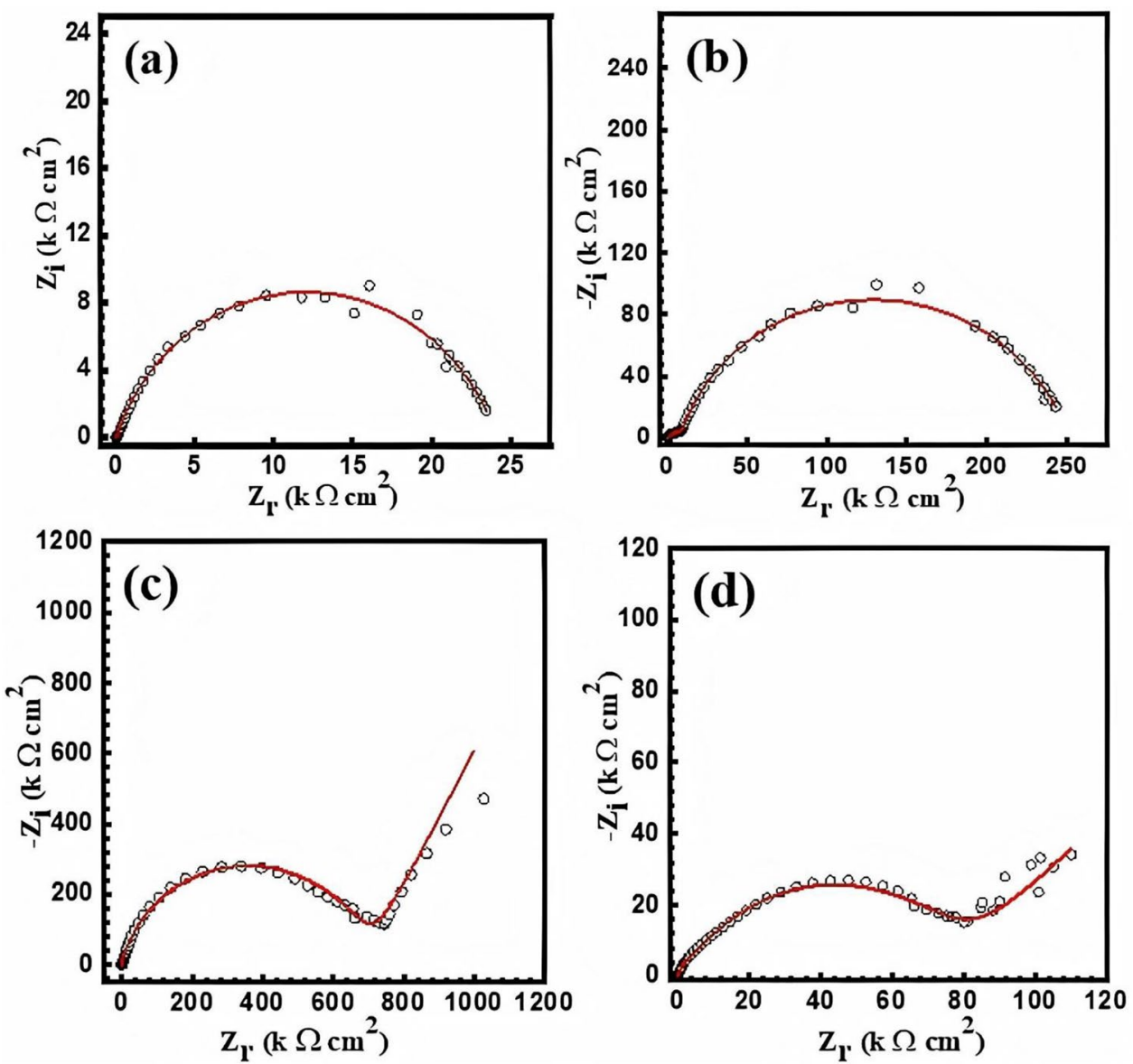

Table 5 EIS parameters of the electrospun PS and PS-NiO nanocomposite SHCs

\begin{tabular}{|c|c|c|c|c|c|c|c|c|c|c|}
\hline Sample & WCA $\left(^{\circ}\right)$ & $\begin{array}{l}R_{p o} \\
\left(\mathrm{k} \Omega \mathrm{cm}^{2}\right)\end{array}$ & $\begin{array}{l}R_{c t} \\
\left(\mathrm{k} \Omega \mathrm{cm}^{2}\right)\end{array}$ & $\begin{array}{l}Y_{01} \\
\left(\mu \Omega^{-1} \mathrm{~cm}^{-2} \mathrm{sn}\right)\end{array}$ & $n_{1}$ & $\begin{array}{l}C_{d l 1} \\
\left(\mu \mathrm{F} \mathrm{cm}^{-2}\right)\end{array}$ & $\begin{array}{c}Y_{02} \\
\mu \Omega\left(^{1} \mathrm{~cm}^{-2} \mathrm{sn}\right. \\
)\end{array}$ & $n_{2}$ & $\begin{array}{l}C_{d l 2} \\
\left(\mu \mathrm{F} \mathrm{cm}^{-2}\right)\end{array}$ & $\begin{array}{l}W \\
\left(\Omega \mathrm{S}^{-1 / 2}\right)\end{array}$ \\
\hline PS & $148^{\circ} \pm 2$ & 5.1 & 24 & 43 & 0.870 & 43 & 10 & 0.852 & 7.3 & - \\
\hline PSN-1 & $151^{\circ} \pm 2$ & 94 & 248 & 2.2 & 0.720 & 1.7 & 1.4 & 0.652 & 0.8 & - \\
\hline PSN-2 & $155^{\circ} \pm 2$ & 179 & 750 & 0.8 & 0.621 & 0.6 & 0.2 & 0.524 & $3.5 \times 10^{-2}$ & $6 \times 10^{-9}$ \\
\hline PSN-3 & $150^{\circ} \pm 2$ & 12 & 81 & 15 & 0.765 & 15 & 6 & 0.681 & 4.3 & $4 \times 10^{-6}$ \\
\hline
\end{tabular}

$X_{\text {cry }}=\frac{\Delta H_{m}}{\Delta H^{\circ}} \times 100$,

where $\Delta H_{m}$ is the melting enthalpy of the electrospun PS and PS-NiO nanocomposite SHCs and $\Delta H^{\circ}$ is the melting enthalpy of the $100 \%$ crystalline PS $\left(53.2 \mathrm{~J} \mathrm{~g}^{-1}\right)[41$, 42]. The calculated values of $T_{\mathrm{g}}, \Delta H_{m}$, and $X_{\text {cry }}$ for PS and PS-NiO nanocomposite SHCs are summarized in Table 3.

\subsection{Thermogravimetric analysis (TGA)}

Due to the thermal degradation that occurred during heat treatment of the PS and PS-NiO nanocomposite SHCs, TGA analysis was studied over a temperature range from 25 to $600{ }^{\circ} \mathrm{C}$ in the presence of $\mathrm{N}_{2}$ as shown in Fig. 7. The calculated temperatures corresponding to the percent of weight loss are listed in Table 4. The thermal decomposition of the 

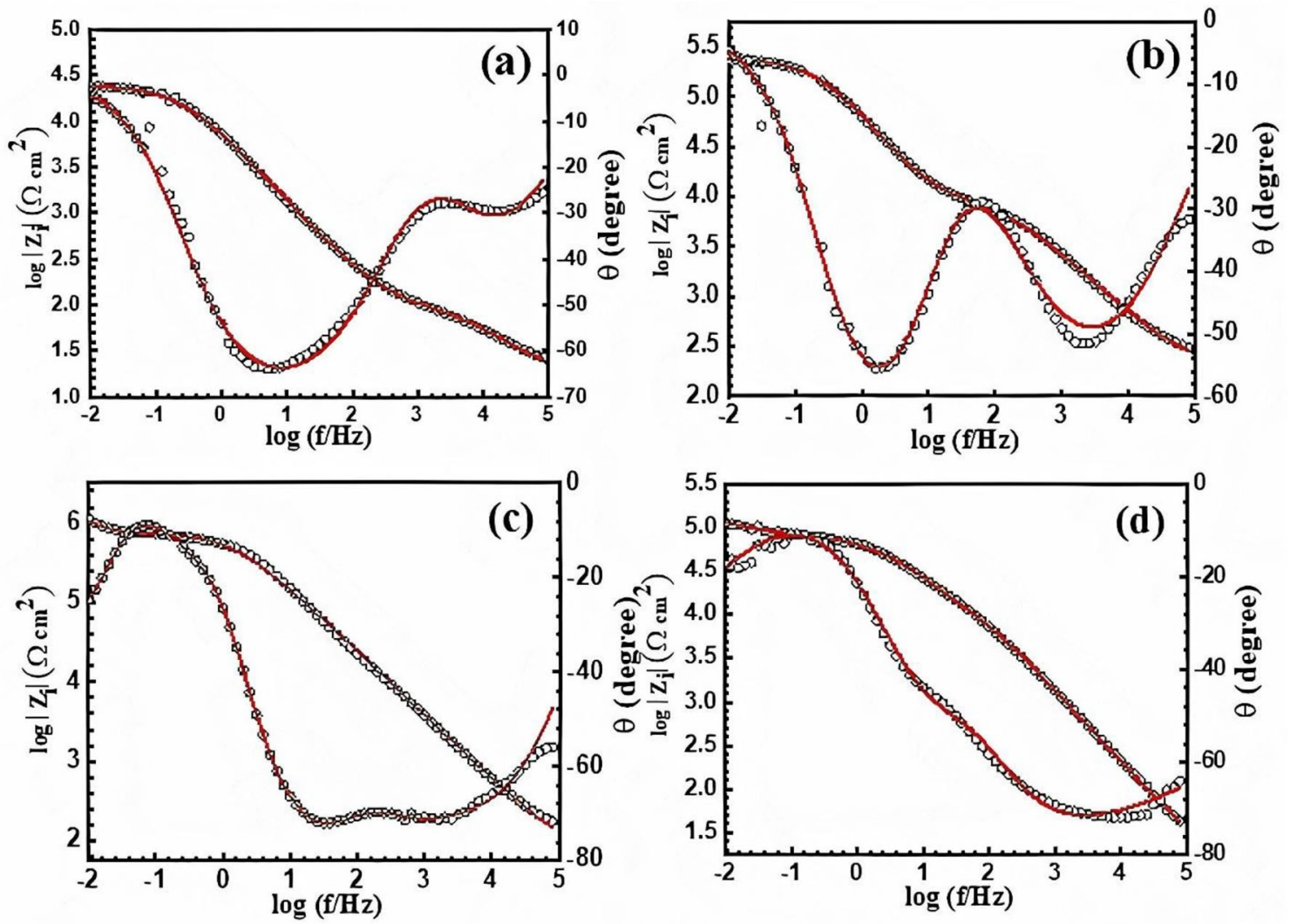

Fig. 10 Bode plots of the as-prepared a PS, b PSN-1, $\mathbf{c}$ PSN-2, and d PSN-3 coatings

prepared coatings was slightly varied for PS before and after $\mathrm{NiO}$ nanoparticles' addition. Pure polystyrene is degraded at around $330{ }^{\circ} \mathrm{C}$ due to the destruction of polymer chains with higher molecular weight [43]. However, at a temperature higher than $500{ }^{\circ} \mathrm{C}$, nothing of the polymer remained due to the entire polymer's decomposition [38]. Chain scission and free radical diffusion are the dominant regimes of thermal degradation of PS. The onset decomposition temperature ( $\left.T_{\text {onset }}\right)$ and the temperature $T_{50}$ and $T_{100}$ are temperatures at which 50 and $100 \%$ of weight losses occur. The $T_{\text {onset }}$ of the as-prepared coatings shifted by $20^{\circ} \mathrm{C}$ to the higher temperature of 354,375 , and $375{ }^{\circ} \mathrm{C}$ for PSN-1, PSN-2, and PSN-3, respectively. This behavior was kept through the thermal decomposition of the samples as the concentration of $\mathrm{NiO}$ nanoparticles increased. Accordingly, the thermal stability of polystyrene is enhanced by $\mathrm{NiO}$ nanoparticles' addition due to the limitation of segmental mobility of the polymer chain provides a physical barrier for free radical diffusion $[44,45]$.

\subsection{Electrochemical impedance spectroscopy (EIS)}

EIS assessed the corrosion resistance of PS and PS-NiO nanocomposite SHCs. Figure $8 \mathrm{a}$ and $\mathrm{b}$ shows the equivalent circuit used to fit the EIS measured results that consist of the electrolyte solution resistance $R_{s}$, double-layer capacitances CPE1 and CPE2 indicating the coating/solution and metal/ solution interface non-ideal capacitances, respectively. The pore resistance and charge transfer resistance are represented by $R_{p o}$ and $R_{c t}$, respectively. In the equivalent circuit, the high impedance value of the frequency intercept $\left(\mid Z_{100} \mathrm{kHz}\right)$ corresponds to the solution resistance $\left(R_{s}\right)$, while the one at the lowest frequency intercept $\left(|Z|_{0.01} \mathrm{~Hz}\right)$ corresponds to the charge transfer resistances $\left(R_{c t}\right)$. The impedance of the CPE is calculated using the Eq. $1 / Z_{\mathrm{CPE}}=Q_{\mathrm{o}}\left(j_{w}\right)^{\alpha}$, where $Q$ 。 (s $\Omega^{-1}$ ) equals the admittance $(1 / / Z \mathrm{Z})$ at $\omega=1 \mathrm{rad} / \mathrm{s}, \omega$ is the 

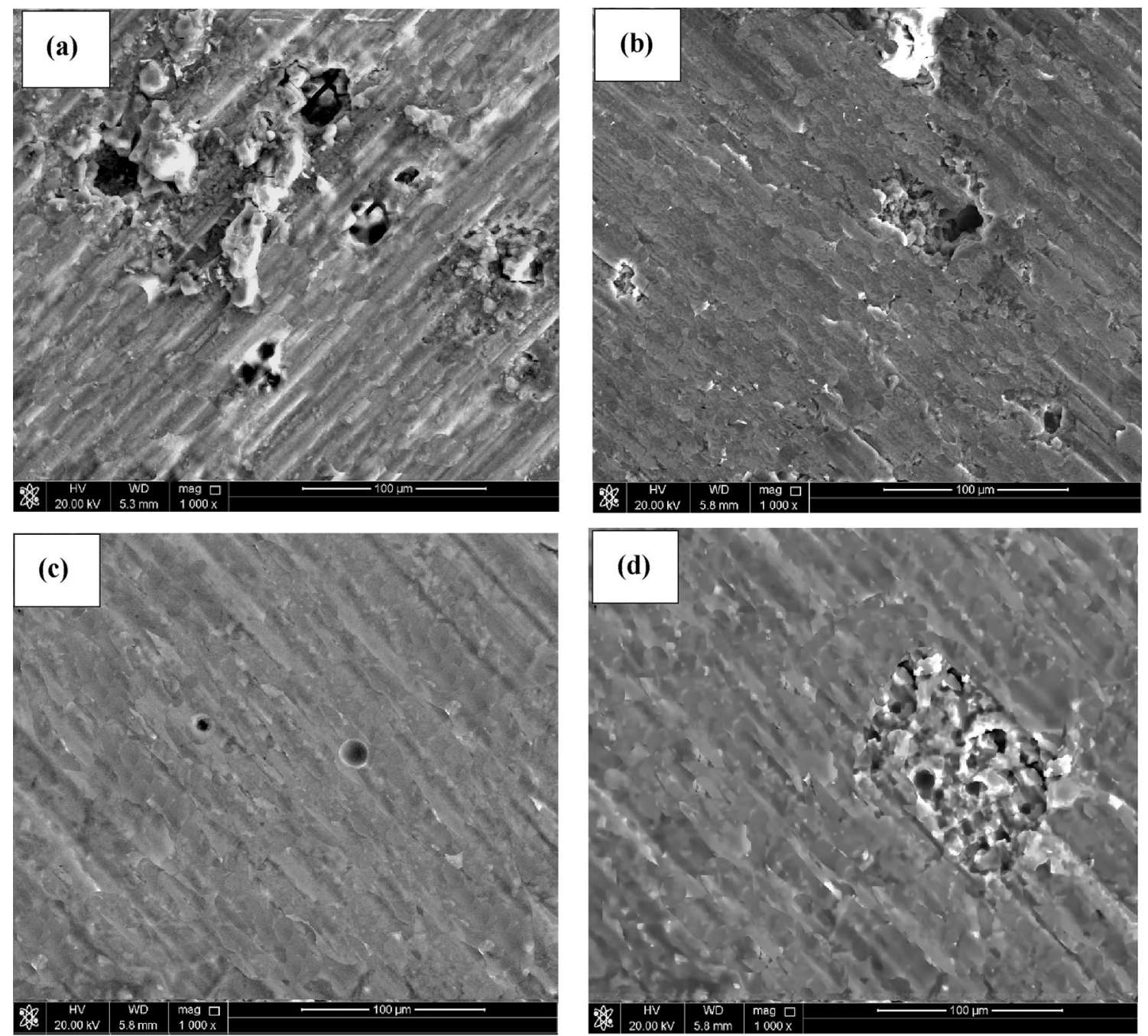

Fig. 11 SEM images of Al alloys after removing the coating from a PS, b PSN-1, $\mathbf{c}$ PSN-2, and $\mathbf{d}$ PSN-3 coatings

angular frequency of the $\mathrm{AC}$ signal (1/rad), and $\alpha$ is the $\mathrm{CPE}$ exponent. The CPE behaves like an ideal capacitor when the value of $\alpha$ is close to 1 .

Besides, the double-layer capacity $C_{d l}$ can be determined from the given equation $[9,46]$ :

$C_{d l}=\sqrt[n]{\frac{Q}{R^{(n-1)}}}$,

where $Q, n$, and $R$ represent the admittance and exponent of constant phase element and resistance, respectively.

Nyquist and Bode plots of PS, PSN-1, PSN-2, and PSN-3 are shown in Fig. 9 and 10, respectively. The dots represent the measured points, while the solid lines represent the fitted data. The calculated electrochemical parameters extracted by the fitting EIS are summarized in Table 5.

The $R_{c t}$ of the PS coating significantly increased from $24 \mathrm{k} \Omega \mathrm{cm}^{2}$ to 248 and $750 \mathrm{k} \Omega \mathrm{cm}^{2}$ for PSN-1 and PSN-2, respectively. The pore resistance $\left(R_{p o}\right)$ of the PS was considerably enhanced from 5.1 to 94 and $179 \mathrm{k} \Omega \mathrm{cm}^{2}$ for PSN-1 and PSN-2, respectively. On the other hand, the $C_{d l}$ decreased with increasing the WCA of the as-prepared coatings, which indicated the charged species' low permittivity to and from the Al surface underneath the coating, see Table 5. This increment in the $R_{c t}$ and $R_{p o}$ could be accredited to the air confined inside the pockets of the rough nanocomposite coatings leading to alleviate the ingress of the hydrated species such as $\mathrm{Cl}^{-}$and $\mathrm{OH}^{-}$. Interestingly, further addition of $\mathrm{NiO}$ nanospecies results in a reduction of $R_{c t}$ and $R_{p o}$ as a result of the aggregation of the nanoparticle on the coating surface, which decreases the surface roughness and the increase in the hydrophilicity due to the increased amount of the metal oxide, which is hydrophilic, leading to a decrease in the WCAH [47] (Fig. 10).

The surface morphology of $\mathrm{Al}$ alloys was explored after removing the as-prepared coatings, as depicted in Fig. 11. 
A distinct variation in the construction of pitting corrosion can be observed due to increasing the corrosion resistance by increasing $\mathrm{NiO}$ content and, accordingly, the WCA. However, further addition of $\mathrm{NiO}$ nanoparticles results in alleviating the WCA and consequently developing pitting corrosion, see Fig. 11d.

\section{Conclusion}

Polystyrene-nickel oxide (PS-NiO) superhydrophobic nanocomposite coatings were successfully fabricated on Al sheets via a one-step electrospinning technique. $\mathrm{NiO}$ nanoparticles' addition has a considerable effect on the wettability, surface roughness, and thermal stability of the polystyrene coating. The morphology of the prepared coating was evaluated and proved the formation of beadedfiber structure. The combination of micro/nanoscale texture of the beaded fibers enhanced the surface roughness of the as-prepared coatings and consequently increased the WCA and reduced the CAH. PSN-2 recorded the highest WCA of $155^{\circ} \pm 2$ and the lowest WCAH of $5^{\circ} \pm 3$ and therefore achieved the maximum corrosion resistance in saline water. Nevertheless, increasing the concentration of $\mathrm{NiO}$ more than that amount reduces the performance of corrosion protection of the as-prepared coating due to the aggregation of $\mathrm{NiO}$ on the coating surface and the increase of hydrophilicity due to the hydrophilic nature of the metal oxides.

Acknowledgements The authors would like to thank the Central laboratory Unit (CLU), Qatar University, for the SEM analysis.

Funding Open access funding provided by the Qatar National Library. This work was supported by (i) the Qatar National Research Fund (QNRF, a member of the Qatar Foundation) through the National Priority Research Program Grant (NPRP) NPRP10-0125-170252 and an (ii) International Research Collaboration Co-Fund grant, IRCC-2021015 provided by Qatar University. Statements made herein are solely the responsibility of the authors.

Open Access This article is licensed under a Creative Commons Attribution 4.0 International License, which permits use, sharing, adaptation, distribution and reproduction in any medium or format, as long as you give appropriate credit to the original author(s) and the source, provide a link to the Creative Commons licence, and indicate if changes were made. The images or other third party material in this article are included in the article's Creative Commons licence, unless indicated otherwise in a credit line to the material. If material is not included in the article's Creative Commons licence and your intended use is not permitted by statutory regulation or exceeds the permitted use, you will need to obtain permission directly from the copyright holder. To view a copy of this licence, visit http://creativecommons.org/licenses/by/4.0/.

\section{References}

1. Ahmed Bahgat R, Aboubakr MA, Nasser AA (2018) Recent advances in corrosion resistant superhydrophobic coatings. Corros Rev 36:127-153

2. Adel MM, Aboubakr Moustafa A, Mariam A-M, Ahmed B (2016) Fundamental, fabrication and applications of superhydrophobic surfaces. In: Ana Z, Maria Carmen M-M (eds) research perspectives on functional micro- and nanoscale coatings. IGI Global, Hershey, PA, pp 341-368

3. Sudhagar S, Sakthivel M, Ajith Arul Daniel S (2020) Application of image processing to radiographic image for quantitative assessment of friction stir welding quality of aluminium 2024 alloy. Measurement 152:107294

4. Abdel-Gaber AM, Abd-El-Nabey BA, Sidahmed IM, El-Zayady AM, Saadawy M (2006) Kinetics and thermodynamics of aluminium dissolution in 1.0M sulphuric acid containing chloride ions. Mater Chem Phys 98:291-297

5. Yin B, Fang L, Tang A-Q, Huang Q-L, Hu J, Mao J-H, Bai G, Bai H (2011) Novel strategy in increasing stability and corrosion resistance for superhydrophobic coating on aluminum alloy surfaces. Appl Surf Sci 258:580-585

6. Badawy WA, Al-Kharafi FM, El-Azab AS (1999) Electrochemical behaviour and corrosion inhibition of $\mathrm{Al}, \mathrm{Al}-6061$ and $\mathrm{Al}-$ $\mathrm{Cu}$ in neutral aqueous solutions. Corros Sci 41:709-727

7. Ahmed AF (2020) Applications of nanomaterials in corrosion protection coatings and inhibitors. Corros Rev 38:67-86

8. Najjar R, Katourani SA, Hosseini MG (2018) Self-healing and corrosion protection performance of organic polysulfide@ureaformaldehyde resin core-shell nanoparticles in epoxy/PANI/ $\mathrm{ZnO}$ nanocomposite coatings on anodized aluminum alloy. Prog Org Coat 124:110-121

9. Radwan AB, Mohamed AMA, Abdullah AM, Al-Maadeed MA (2016) Corrosion protection of electrospun PVDF-ZnO superhydrophobic coating. Surf Coat Technol 289:136-143

10. Lee KH, Kim HY, Bang HJ, Jung YH, Lee SG (2003) The change of bead morphology formed on electrospun polystyrene fibers. Polymer 44:4029-4034

11. Huang Z-M, Zhang YZ, Kotaki M, Ramakrishna S (2003) A review on polymer nanofibers by electrospinning and their applications in nanocomposites. Compos Sci Technol 63:2223-2253

12. Sukigara S, Gandhi M, Ayutsede J, Micklus M, Ko F (2003) Regeneration of Bombyx mori silk by electrospinning-part 1: processing parameters and geometric properties. Polymer 44:5721-5727

13. Demir MM, Yilgor I, Yilgor E, Erman B (2002) Electrospinning of polyurethane fibers. Polymer 43:3303-3309

14. Fong H, Chun I, Reneker DH (1999) Beaded nanofibers formed during electrospinning. Polymer 40:4585-4592

15. Bahgat Radwan AMAA, Mohamed AMA, Al-Maadeed MA (2018) New electrospun polystyrene/ $/ \mathrm{Al}_{2} \mathrm{O}_{3}$ nanocomposite superhydrophobic coatings; synthesis, characterization, and application. Coatings 8:65 
16. Ku PL (1988) Polystyrene and styrene copolymers. I. Their manufacture and application. Adv Polym Technol 8:177-196

17. Hou W, Wang Q (2007) Wetting behavior of a $\mathrm{SiO}_{2}$-polystyrene nanocomposite surface. J Colloid Interface Sci 316:206-209

18. Hou W, Wang Q (2009) UV-driven reversible switching of a polystyrene/titania nanocomposite coating between superhydrophobicity and superhydrophilicity. Langmuir 25:6875-6879

19. Xu X, Zhang Z, Guo F, Yang J, Zhu X, Zhou X, Xue Q (2012) Fabrication of bionic superhydrophobic manganese oxide/polystyrene nanocomposite coating. J Bionic Eng 9:11-17

20. Zhao Y, Xing C, Zhang Z, Yu L (2017) Superhydrophobic polyaniline/polystyrene micro/nanostructures as anticorrosion coatings. React Funct Polym 119:95-104

21. Pawar PG, Xing R, Kambale RC, Kumar AM, Liu S, Latthe SS (2017) Polystyrene assisted superhydrophobic silica coatings with surface protection and self-cleaning approach. Prog Org Coat 105:235-244

22. Feng L, Yan Z, Qiang X, Wang Y, Liu Y (2015) Polystyrenegrafted $\mathrm{Al}$ surface with excellent superhydrophobicity and corrosion resistance. Surf Interface Anal 47:506-513

23. Bahgat Radwan A, Abdullah AM, Hassan MK (2018) The missing piece of the puzzle regarding the relation between the degree of superhydrophobicity and the corrosion resistance of superhydrophobic coatings. Electrochem Commun 91:41-44

24. Zhan N, Li Y, Zhang C, Song Y, Wang H, Sun L, Yang Q, Hong X (2010) A novel multinozzle electrospinning process for preparing superhydrophobic PS films with controllable bead-on-string/microfiber morphology. J Colloid Interface Sci 345:491-495

25. Jarusuwannapoom T, Hongrojjanawiwat W, Jitjaicham S, Wannatong L, Nithitanakul M, Pattamaprom C, Koombhongse P, Rangkupan R, Supaphol P (2005) Effect of solvents on electro-spinnability of polystyrene solutions and morphological appearance of resulting electrospun polystyrene fibers. Eur Polym J 41:409-421

26. Baba EM, Cansoy CE, Zayim EO (2016) Investigation of wettability and optical properties of superhydrophobic polystyrene- $\mathrm{SiO}_{2}$ composite surfaces. Prog Org Coat 99:378-385

27. Hooda A, Goyat MS, Gupta R, Prateek M, Agrawal M, Biswas A (2017) Synthesis of nano-textured polystyrene/ $\mathrm{ZnO}$ coatings with excellent transparency and superhydrophobicity. Mater Chem Phys 193:447-452

28. Hosny NM, Gomaa I, Abd El-Moemen A, Anwar ZM (2020) Synthesis, magnetic and adsorption of dye onto the surface of $\mathrm{NiO}$ nanoparticles. J Mater Sci Mater Electron 31:8413-8422

29. Pan C, Ding R, Hu Y, Yang G (2013) Electrospinning fabrication of rime-like $\mathrm{NiO}$ nanowires/nanofibers hierarchical architectures and their photocatalytic properties. Phys E 54:138-143

30. Gowd EB, Nair SS, Ramesh C (2002) Crystalline transitions of the clathrate $(\delta)$ form of syndiotactic polystyrene during heating: studies using high-temperature $\mathrm{X}$-ray diffraction. Macromolecules 35:8509-8514

31. Rajak A, Hapidin DA, Iskandar F, Munir MM, Khairurrijal K (2020) Electrospun nanofiber from various source of expanded polystyrene (EPS) waste and their characterization as potential air filter media. Waste Manag 103:76-86

32. Huan S, Bai L, Liu G, Cheng W, Han G (2015) Electrospun nanofibrous composites of polystyrene and cellulose nanocrystals: manufacture and characterization. RSC Adv 5:50756-50766
33. Liang CY, Krimm S (1958) Infrared spectra of high polymers. VI. Polystyrene. J Polym Sci 27:241-254

34. Haridas AK, Sharma CS, Sritharan V, Rao TN (2014) Fabrication and surface functionalization of electrospun polystyrene submicron fibers with controllable surface roughness. RSC Adv 4:12188-12197

35. Al-Kadhemy MFH, Rasheed ZS, Salim SR (2016) Fourier transform infrared spectroscopy for irradiation coumarin doped polystyrene polymer films by alpha ray. J Radiat Res Appl Sci 9:321-331

36. Ariyanta HA, Ivandini TA, Yulizar Y (2021) Novel NiO nanoparticles via phytosynthesis method: structural, morphological and optical properties. J Mol Struct 1227:129543

37. Sabouri Z, Akbari A, Hosseini HA, Khatami M, Darroudi M (2020) Egg white-mediated green synthesis of $\mathrm{NiO}$ nanoparticles and study of their cytotoxicity and photocatalytic activity. Polyhedron 178:114351

38. Soleimani E, Mohammadi M (2018) Synthesis, characterization and properties of polystyrene/NiO nanocomposites. J Mater Sci Mater Electron 29:9494-9508

39. Kong Y, Hay JN (2003) The enthalpy of fusion and degree of crystallinity of polymers as measured by DSC. Eur Polym J 39:1721-1727

40. Padmaraj O, Venkateswarlu M, Satyanarayana N (2013) Effect of $\mathrm{ZnO}$ filler concentration on the conductivity, structure and morphology of PVdF-HFP nanocomposite solid polymer electrolyte for lithium battery application. Ionics 19:1835-1842

41. Pasztor AJ, Landes BG, Karjala PJ (1991) Thermal properties of syndiotactic polystyrene. Thermochim Acta 177:187-195

42. Hikosaka S, Ohki Y (2011) Effect of tacticity on the dielectric properties of polystyrene. IEEJ Trans Electr Electron Eng 6:299-303

43. Asaletha R, Kumaran MG, Thomas S (1998) Thermal behaviour of natural rubber/polystyrene blends: thermogravimetric and differential scanning calorimetric analysis. Polym Degrad Stab 61:431-439

44. García-Cerda LA, Romo-Mendoza LE, Quevedo-López MA (2009) Synthesis and characterization of NiO nanoparticles and their PMMA nanocomposites obtained by in situ bulk polymerization. J Mater Sci 44:4553-4556

45. Chrissafis K, Bikiaris D (2011) Can nanoparticles really enhance thermal stability of polymers? Part I: an overview on thermal decomposition of addition polymers. Thermochim Acta 523:1-24

46. Ubaid F, Radwan AB, Naeem N, Shakoor RA, Ahmad Z, Montemor MF, Kahraman R, Abdullah AM, Soliman A (2019) Multifunctional self-healing polymeric nanocomposite coatings for corrosion inhibition of steel. Surf Coat Technol 372:121-133

47. Bahgat Radwan A, Ali K, Shakoor RA, Mohammed H, Alsalama T, Kahraman R, Yusuf MM, Abdullah AM, Fatima Montemor M, Helal M (2018) Properties enhancement of Ni-P electrodeposited coatings by the incorporation of nanoscale $\mathrm{Y}_{2} \mathrm{O}_{3}$ particles. Appl Surf Sci 457:956-967

Publisher's Note Springer Nature remains neutral with regard to jurisdictional claims in published maps and institutional affiliations. 